\title{
Research on Information Design and Communication of Digital Media Ting Sun
}

\author{
School of art and design, HanKou University
}

\section{Keywords:Digital media era;Information design;communication}

\begin{abstract}
Since new digital media era is coming, it puts forward new requirements for the design and communication of information. In this paper, with the help of the overview of information design and information communication, it explores the ways to realize the information design and information communication of digital media.
\end{abstract}

\section{Introduction}

With the development of mew digital media era, information design can convey information more conveniently, more accurately, which can be much easier to be identified, thus, it can have more attraction and value. With the effect of broadband network, the most important thing is we are not lack of information, but more important thing is how each of us can have more convenient access to the valuable information. Massive information of the global Internet as well as data storage is no longer limited by the limited capacity of storage media as in the past, but also is free from the constraints of time or place, which theoretically can have infinite rich resources to be shared. However, with the high-speed development of the bandwidth going into public environment and family, it does not mean that the valuable information and entertainment services will be followed, therefore, the key of providing information service is to provide information with imagination as well as imaginative design.

\section{The Overview of Information Design and Information Communication}

\section{The Interpretation of Information Design}

Information design is a new emerging discipline, so far, there is no unified definition and so on, which was originated in 1990's.International design education circles have no professional titles and teaching focus on the definition, many Japanese universities have set up the majors or engaged in the professional disciplines, such as Tama Art University, Tokyo University of Arts, University of Tsukuba, Japanese name is called as "intelligence design"; the major of interface design in Kobe Design University of Japan, US and Europe called it as: "Kommun ikations design", "Medienund Design", "Web Design", "multimedia design", "media and virtual reality design (M/MVR)". In 1999, in Japan, Tama Art University held the International Symposium on information design, it officially used the the English name of this discipline as "INFORMATION DESIGN". From the involved field of the exploring problems, and the professional courses of many universities as well as the personnel training and international foundation study with the trend of social development, we can summarize the contents of study and the object of study of information design as follows (Fig. 1):

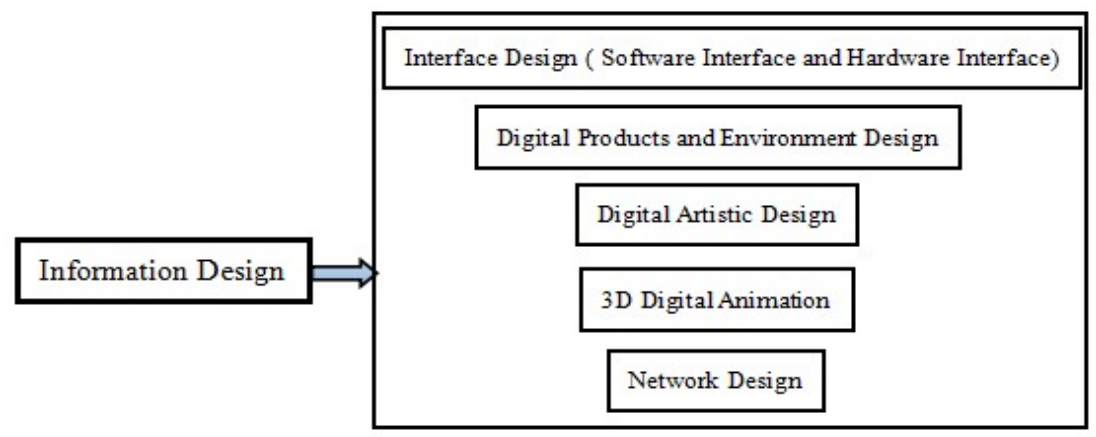

Fig. 1 The extension of information design 
In the era of industrialization, the mode of production is characterized with the industrial mass production as the main characteristics, in order to make people can make better use of machines, the focus of industrial design is to improve the friendly feedback when people are connected with machines through better physical design, reasonable scale, texture and shape and so on. While in the information society, intelligent and digital production, virtual design and manufacturing as well as digital "operation" will be the main feature of the mode of production. The modern manufacturing industry is moving towards information era. Therefore, "information design" can relatively more accurate express the connotation and essence of modern design.

\section{The Interpretation of Information Communication}

Information communication can also be called as information diffusion, information flow and so on. In the early days, the personnel of researching it are mostly market experts, epidemiologists and sociologists, whose main research work is to analyze the propagation in real social network with innovation,epidemic and product, however, it is very difficult to have access to the massive data in the real social network, so the study of these researchers usually includes questionnaires to obtain data, so the data set they used is very small, and most of them are some qualitative research.

Communication is the interactive action between people and outside world with the information as the media, the purpose of communication is to transmit the information mutually to the recipient, which can make the recipient know this information. There are many ways of information communication, the most direct purpose of creating symbols is to generalize information communication, information design is a way with the visual language especially with the image system to transmit information, the communication of designing symbolic information has the characteristics of the general symbolic communication, designing symbol is the final carrier to achieve communication. Therefore, communication is a process of symbol and symbolic interpretation. The communication process of information design is shown as in Figure 2:

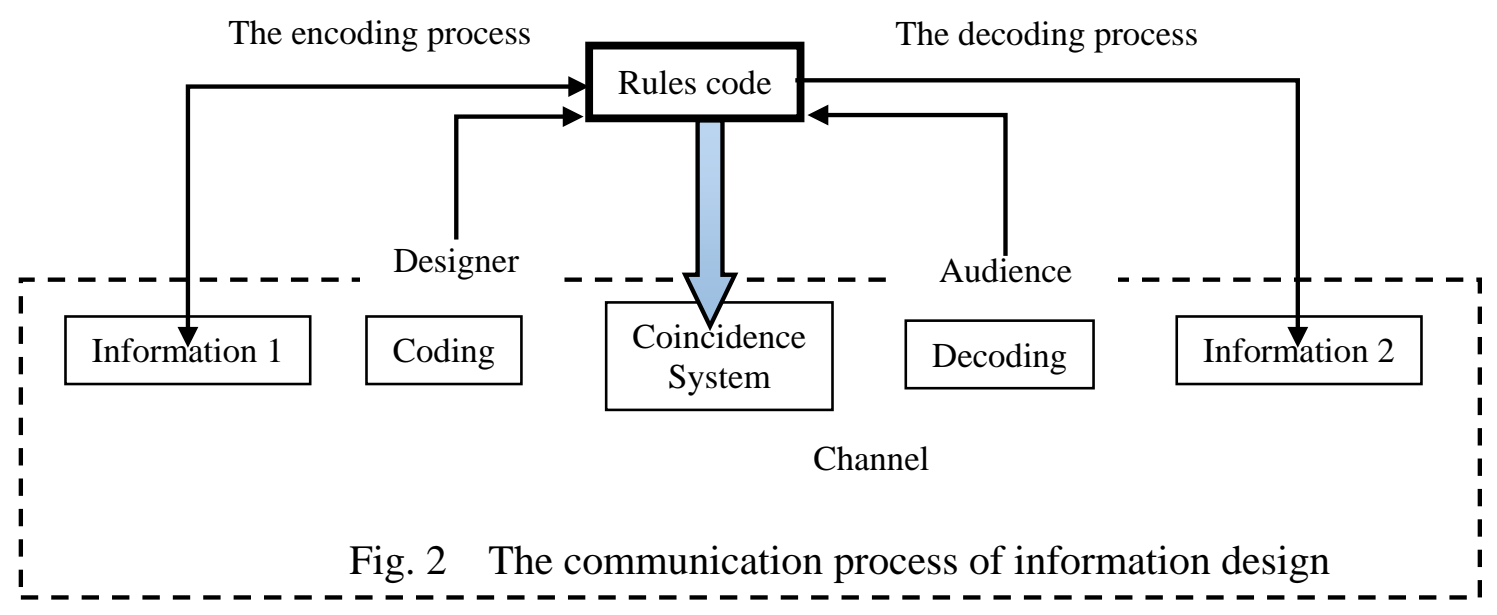

Context

\section{Analysis on Information Design and Information Communication Reroute in Digital Media}

In the era of information technology, the traditional media design has new breakthrough, the emergence of new media, such as digital media has its new propagation characteristics, which is incomparable with the traditional media, it is a process-oriented dynamic design, at the same time, it is more comprehensive and closer to the users.

\section{Taking the Audience as the Center}

Due to the rapid development of computer technology, digital media is more interactive, which has closer relationship between new media and audience. During the actual process of information communication, the new media puts more attention and concern to the user than the traditional 
media, which pays attention to the use and participation of the users, paying attention the user's related psychological experience in the interaction between users and media, putting focus on the user's satisfaction with media and information. This makes the new information design and communication pay more attention to the audience and take audience as the center. Before designing, the related designers must carefully analyze the relevant audience firstly, determining the scope of the target audience. Because the users are complicated in some degree, which brings and increases the difficulty for the traditional media to get comprehensive information from the audience. Interactive While with the interactive feature of the digital media, during the process of using the specific information, the audience can give feedback from their own experience, which makes it possible for the audience to spread customization information and hence the target of information communication.

\section{The Information Design and Communication is with More Comprehensive Feature}

First of all, in the era of information technology, information design and communication is a comprehensive project system, which has wider interfaces, combining with art and technology, unifying form and content. For any media, content is an important part of information design, which is the key of the communication process, although the technology can create forms, but it is difficult to replace content, so does the digital media. On the basis of digital media, the element of information design and communication is the interface, structure and content.Among them, the information structure reflects the connection of information, which is the result of the organization and architecture of information in accordance with the actual communication objectives; while the interface can reflect the information content and structure, which is the place where the audience can get information and information system can launch the interaction. Therefore, the main part of digital media design is: information interface design, information architecture, digital content design (shown in Fig. 3).

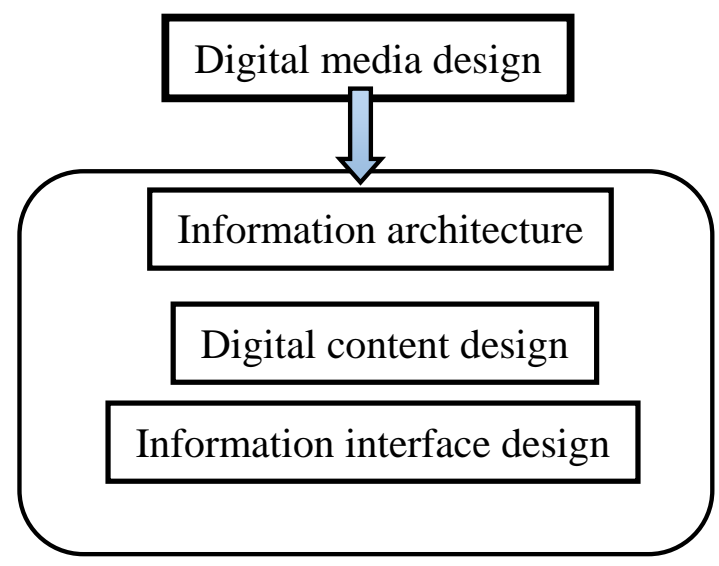

Fig. 3 The composition of digital media design

\section{Conclusion}

In short, in the era of information, science and technology is developing at high speed, the demands of human life, work, study and recreation are also changing, designing theory, as well as designing methods need to be updated, and people-oriented design is the eternal principle. Innovation is always the key, the innovation of design should be parallel with design idea and method of innovation. On one hand, the concept should be updated continuously, scientific application should be adapted to new technology constantly, on the other hand, cultivating a large number of outstanding talents is the key to win the future. 


\section{Reference}

[1] Mary E.Hocks and Michelle R.Kendrick, 2003, Eloquent Images: Word and Image in the Age of New Media, Massachusetts Institute of Technology, pp24-26.

[2] Richard Florida, 2002, The Rise of the Creative Class: And How It's Transforming Work, Leisure, Community and Everyday Life, Perseus Books Group, pp47-49.

[3] Sanders, M. S. \& McCormick, E. J. 1987, Human Factors in Engineering and Design, McGraw-Hill, New York, pp42-43.

[4] Springer, 2003, Mapping Scientific Frontiers: The Quest for Knowledge Visualization, Singapore, Kyodo Printing Co Pte Ltd, pp31-33.

[5] Nahum D. Gershon, Stephen G. Eick, 1997, Information Visualization, IEEE Computer Graphics and Applications, vol.15, pp.29-31. 